\title{
Examining Citizens' Expectations and Perceptions in regards to Service Quality in Public Sector: Adapting a Hybrid Public Service Quality Model to the Georgian context
}

\author{
Nino Pataraia, Tamar Jinchveladze, Tamar Magalashvili \\ Ilia State University, Georgia
}

\begin{abstract}
Purpose

This empirical study examined citizens' expectations and perceptions in regards to service quality in three major Georgian public institutions.

\section{Design/methodology/approach}

The given research adopted a mixed method approach. The perspectives of public entities' representatives in relation to service quality management were investigated through in-depth interviews, whereas expectations and perceptions in regards to services to be offered or acquired in the context of public institutions were studied through a printed questionnaire utilizing a hybrid model of SERVQUAL integrating private and public service quality dimensions. This paper presents results of a quantitative study conducted on a sample of 310 citizens, equally distributed across public sector institutions, illustrating factor analysis of survey data. For factor extraction, rotation and interpretation, Oblimin rotation technique was used, determining inter-correlation among the service factors.
\end{abstract}

\section{Findings}

Findings of this study suggest new arrangements of components loading on a number of newly revealed factors associated with public service quality. Different items of initial quality dimensions were rotated under newly created factors: reliability-in-relations, empathy, responsiveness, reliability, assistance, trustworthiness and transparency. The newly developed hybrid Public Service Quality model will assist public sector institutions in developing service quality management system considering the revealed factors related to citizens' expectations and perceptions of public sector service quality. 


\section{International Conference on New Trends in \\ Management, Business and Economics}

\section{Originality}

This is the first attempt to carry out a mixed-method study approach to researching Public Service Quality in the Georgian context, integrating perspectives of both key players, service providers and receivers. The primary contribution of this study is that it has tested a hybrid model for measuring perceived public service quality, integrating both service quality dimensions from public and private sectors, and proposed a refined model fit for the Georgian public sector context.

Keywords: factor analysis; public institution; public service quality dimensions; service quality management; SERVQUAL hybrid model 